\title{
A phase II study of weekly docetaxel and cisplatin plus oral tegafur/uracil and leucovorin as first-line chemotherapy in patients with locally advanced or metastatic gastric cancer
}

\author{
C-P Lii, ${ }^{*, 1,2}$, J-S Chen ${ }^{3}$, L-T Chen ${ }^{4,5}$, C-J Yen ${ }^{6}$, K-D Lee ${ }^{7}$, W-P Su ${ }^{6}$, P-C Lin ${ }^{6}$, C-H Lu', H-J Tsai ${ }^{5}$ and Y Chao ${ }^{*, 2,8}$ \\ 'Division of Gastroenterology, Department of Medicine, Taipei Veterans General Hospital, No. 20 I, Sec. 2, Shih-Pai Road, Taipei II 217 , Taiwan; \\ ${ }^{2}$ National Yang-Ming University School of Medicine, Taipei, Taiwan; ${ }^{3}$ Division of Hematology-Oncology, Department of Internal Medicine, Chang Gung \\ Memorial Hospital and Chang Gung University, Taoyuan County, Taiwan; ${ }^{4}$ Division of Cancer Research, National Health Research Institutes, Miaoli \\ County, Taiwan; ${ }^{5}$ Department of Internal Medicine, Kaohsiung Medical University Hospital, Kaohsiung, Taiwan; ${ }^{6}$ Division of Hematology/Oncology, \\ Department of Internal Medicine, National Cheng Kung University Hospital, Tainan, Taiwan; ${ }^{7}$ Department of Hematology, Chang Gung Memorial \\ Hospital, Chiayi, Taiwan; ${ }^{8}$ Cancer Center, Taipei Veterans General Hospital, No. 201, Sec. 2, Shih-Pai Road, Taipei 11217 , Taiwan
}

\begin{abstract}
BACKGROUND: Docetaxel plus cisplatin and 5-fluorouracil has become a new standard for treating advanced gastric cancer. However, high rates of severe neutropenia limit its application. Modification of the regimen could be the solution to get similar activity but less myelosuppression. METHODS: Patients with histologically confirmed, locally advanced, or recurrent/metastatic gastric adenocarcinoma without previous chemotherapy were enrolled. This regimen consisted of docetaxel (Tyxan, TTY, Taipei, Taiwan) 30-min infusion at a dose of $36 \mathrm{mg} \mathrm{m}^{-2}$, followed by cisplatin $30 \mathrm{mg} \mathrm{m}^{-2}$ infusion over I h on days I and 8, and oral tegafur/uracil $300 \mathrm{mg} \mathrm{m}^{-2}$ per day plus leucovorin $90 \mathrm{mg}$ per day on days 1-14, every 3 weeks. Tumour response was evaluated after every 2 cycles of treatment.

RESULTS: From August 2007 to March 2009, 45 patients were enrolled. The median age was 56 years (range: 22-75). Among the 40 patients evaluable for tumour response, one achieved a complete response, 22 had partial responses and I I had stable disease. The overall response rates of the evaluable and intent-to-treat (ITT) populations were 58\% (95\% Cl: $41-74 \%)$ and 53\% (95\% Cl: 38-68\%), respectively. The disease control rates in these populations were $85 \%$ (95\% Cl: $70-94 \%)$ and $82 \%$ (95\% Cl: 68-92\%), respectively. In the ITT analysis, the median time to progression and overall survival were 6.8 and 13.9 months, respectively. Major grade 3-4 toxicities were neutropenia (51\%), anaemia (22\%), diarrhoea (16\%), and infections (20\%). No patient died of treatment-related toxicities. CONCLUSION: Concurrent weekly docetaxel and cisplatin plus oral tegafur/uracil and leucovorin are effective and well tolerated in the treatment of advanced gastric cancer.
\end{abstract}

British Journal of Cancer (20 I0) I 03, I343- 1348. doi:I0.1038/sj.bjc.6605928 www.bjcancer.com

Published online 5 October 2010

(c) 2010 Cancer Research UK

Keywords: docetaxel; cisplatin; tegafur/uracil; leucovorin; gastric cancer

Gastric cancer is one of the leading causes of cancer death worldwide (Roder, 2002). Although an early-stage disease can be treated with curative resection, most patients show locally advanced or metastatic disease on diagnosis. Furthermore, recurrent tumours are observed in up to $50 \%$ of the patients treated by curative intention using standardised surgical techniques (McNeer et al, 1951; Dupont et al, 1978). The prognosis is generally poor, with an overall 5-year survival of approximately $20 \%$ in most countries. The median survival time for patients who presented with advanced or metastatic diseases and had the best supportive care was only 3-5 months (Verdecchia et al, 2003).

With the introduction of novel drug administration schedules and the emergence of new chemotherapeutic agents, modern

\footnotetext{
*Correspondence: Dr C-P Li or Dr Y Chao; E-mails: cpli@vghtpe.gov.tw or ychao@vghtpe.gov.tw

This study was presented at the 2010 Gastrointestinal Cancers Symposium, 22-24 January 2010, Orlando, FL, USA.

Received 7 June 2010; revised 26 August 2010; accepted 2 September 20 I0; published online 5 October 2010
}

systemic chemotherapy can achieve $30-60 \%$ objective response rates in advanced gastric cancers (Schoffski, 2002). However, the overall survival (OS) remains consistently around 9-11 months, in the expenditure of significant treatment-related toxicities (Ohtsu, 2005). New treatments with better therapeutic indexes are very important for clinical management of these patients.

The non-overlapping toxicity profile of docetaxel, cisplatin, and oral fluoropyrimidine, as well as the observations of scheduledependent synergism among docetaxel, cisplatin, and oral fluoropyrimidine in human gastric carcinoma xenografts (Maeda et al, 2004; Kodera et al, 2005), warrants such a combination to be evaluated in treating advanced gastric cancers. Recently, a multicenter, open-label, randomised phase III trial (V325) was conducted to evaluate the safety and efficacy of docetaxel for treating patients with advanced gastric adenocarcinoma (Van Cutsem et al, 2006). The patients were randomised to receive either the investigational arm of the triplet combination of docetaxel, cisplatin, and 5-fluorouracil (5-FU) (DCF), or the reference standard regimen of cisplatin and 5-FU. Both overall response rate (37 vs 25\%) and time to progression (TTP) (5.6 vs 3.7 months) 
favored the DCF arm over the CF arm. The median OS was also significantly longer for the DCF arm than the CF arm (9.2 vs 8.6 months). These findings represent an important milestone in the treatment of patients with advanced gastric cancer and show that DCF can become a new standard for treating advanced gastric cancer. However, grade 3 or 4 neutropenia occurred in $82 \%$ of patients on DCF, including $29 \%$ with complicated neutropenia. The high rates of severe myelosuppression in the V325 study could have been caused by (1) the 3-weekly regimen of docetaxel, (2) high-dose cisplatin, and (3) 5-day continuous infusion of 5-FU.

To overcome the significant myelosuppression, weekly docetaxel at a dose of $36 \mathrm{mg} \mathrm{m}^{-2}$ and cisplatin $30 \mathrm{mg} \mathrm{m}^{-2}$ was used to replace the 3-weekly regimen, based on the previous reports that a relatively lower dosage and a weekly regimen had similar efficacy and better tolerability than the standard 3-weekly regimen (Kunitoh et al, 1996; Hainsworth et al, 1998; Chen et al, 2002; Schuette et al, 2005). Oral tegafur/uracil was used to replace the 5 -days continuous infusion of 5-FU. This phase II study of combination chemotherapy of weekly docetaxel, cisplatin, and oral tegafur/uracil and leucovorin was conducted to determine if this regimen could achieve activity similar to the original schedule in the V325 study and be more tolerable for Asian patients with advanced gastric adenocarcinoma.

\section{PATIENTS AND METHODS}

\section{Study design and patients}

This was a prospective, multi-center, phase II clinical trial of docetaxel and cisplatin plus oral tegafur/uracil and leucovorin in patients with advanced gastric cancer. The primary objective was to determine the objective response rate in patients with advanced gastric cancer. Secondary objectives included TTP, duration of objective response, OS, and safety profiles.

Eligibility criteria of patients included (1) pathologically confirmed, locally advanced (unresectable), recurrent or metastatic gastric adenocarcinoma, including gastroesophageal junction tumours; (2) measurable disease by imaging studies; (3) no previous chemotherapy except for postoperative adjuvant chemotherapy received more than 6 months before entry into the study; (4) ECOG (Eastern Cooperative Oncology Group) performance status $\leqslant 2$; (5) age between 20 and 75 years; and (6) adequate hepatic, renal, and bone marrow functions, including aspartate aminotransferase/ alanine aminotransferase $\leqslant 2.5$ times the upper limit of normal) (ULN) ( $\leqslant 5.0$ times the ULN if hepatic metastasis), alkaline phosphatase $\leqslant 2.5$ times the ULN $(\leqslant 5.0$ times the ULN if bone metastasis), total bilirubin $\leqslant 1.5$ times the ULN, creatinine $\leqslant 1.0$ times the ULN, haemoglobin $\geqslant 9 \mathrm{~g}$ per $100 \mathrm{ml}$, absolute neutrophil count $($ ANC) $\geqslant 1500$ per $\mu \mathrm{l}$, and platelets $\geqslant 100000$ per $\mu \mathrm{l}$.

Exclusion criteria included (1) pre-existing peripheral neuropathy; (2) pregnancy, breastfeeding, or woman of child-bearing potential without adequate contraception; (3) concurrent or previous malignancy; (4) central nervous system metastases; (5) uncontrolled infection; (6) concurrent treatments that might interfere with the study evaluation; and (7) inability to take the study medication orally.

This study was approved by the ethics committees of all participating institutes and signed informed consent was obtained from all patients.

\section{Chemotherapy protocol}

Docetaxel (Tyxan, TTY Biopharm, Taipei, Taiwan) 30-min infusion at a dose of $36 \mathrm{mg} \mathrm{m}^{-2}$, followed by cisplatin $30 \mathrm{mg} \mathrm{m}^{-2}$ infusion over $1 \mathrm{~h}$ on days 1 and 8 , and oral tegafur/uracil (UFUR) $300 \mathrm{mg} \mathrm{m}^{-2}$ per day plus leucovorin (Folina) $90 \mathrm{mg}$ per day on days $1-14$, every 21 days, was administered. To reduce the risk of hypersensitivity reactions to docetaxel, all patients were premedicated with oral dexamethasone $8 \mathrm{mg}$ twice daily for 3 days starting 1 day before docetaxel, or intravenous dexamethasone $10 \mathrm{mg} 30 \mathrm{~min}$ before receiving docetaxel.

The total dose of cisplatin was dissolved in $250 \mathrm{ml}$ of sterile saline and infused over a 1-hour period. Pretreatment hydration with 1-21 of fluids infused before cisplatin dose was recommended. The total daily dose of tegafur/uracil was determined and rounded to the nearest $100 \mathrm{mg}$ and divided into three doses given $8 \mathrm{~h}$ apart. If the total number of tablets could not be evenly divided, the highest dose was given in the morning and the lower doses in the afternoon or evening. Cycles were repeated every 3 weeks or on recovery from toxicities to baseline or grade 1 (except for alopecia and anaemia).

\section{Dose modification}

Dose modifications were based on haematologic and nonhaematologic toxicities. Haematology test was performed every week to monitor haematologic recovery. Chemotherapy doses were reduced or treatment was delayed for no more than 2 weeks to allow patients to recover from toxicities. The dose of each study drug was reduced stepwise. Level-1 was docetaxel $30 \mathrm{mg} \mathrm{m}^{-2}$, cisplatin $25 \mathrm{mg} \mathrm{m}^{-2}$, tegafur/uracil $200 \mathrm{mg} \mathrm{m}^{-2}$, and leucovorin $90 \mathrm{mg}$ per day. Level-2 was docetaxel $25 \mathrm{mg} \mathrm{m}^{-2}$ and cisplatin $20 \mathrm{mg} \mathrm{m}^{-2}$, whereas tegafur/uracil and leucovorin were withdrawn. A maximum of two dose level reductions were allowed per patient and any patient who required more was excluded from the treatment protocol.

If a haematology test within $72 \mathrm{~h}$ before the next cycle indicated a neutrophil count $<1500$ per $\mathrm{mm}^{3}$ or a platelet count $<100000$ per $\mathrm{mm}^{3}$, the next cycle was delayed until haematologic recovery. At haematologic nadir, if the neutrophil count was $<1000 \mathrm{~mm}^{3}$ or platelets was $<50000 \mathrm{~mm}^{3}$, the next dose was reduced by one level on day 1 of a new cycle. If the neutrophil count was $<1000 \mathrm{~mm}^{3}$ or the platelet count was $<50000 \mathrm{~mm}^{3}$ on day 8 within a cycle, the chemotherapy was omitted. The prophylactic use of recombinant granulocyte colony-stimulating factor (G-CSF) was not permitted. However, if a patient develops grade 4 neutropenia (ANC $<500$ per $\mathrm{mm}^{3}$ ), the use of recombinant G-CSF was allowed for subsequent cycles.

Chemotherapy administration was resumed at the same dose level during the cycle on recovery from non-haematologic toxicities to the baseline or grade 1 (except for alopecia and anaemia). If such recovery was not achieved before day 8 from the scheduled date, the chemotherapy dose was skipped on day 8 . The next dose was reduced by one level. If a patient developed grade 1 or 2 nephrotoxicity (creatinine 1.0-3.0 times the ULN), cisplatin was omitted, and then reduced one dose level in the next dose on recovery to grade 1 . If more than two reductions of dose level were needed, the patient was withdrawn from the study. If grade 3 or 4 nephrotoxicity ( $>3.0$ times the ULN) occurred, the patient was withdrawn from the study. If diarrhoea greater than grade 2 occurred, tegafur/uracil and leucovorin were reduced one dose level plus the patient was given appropriate treatment for diarrhoea. If it reappeared, then the patient was withdrawn from the study. When toxicity subsided to baseline or less than grade 1, administration was resumed. Therapy was withheld until recovery for a maximum of 2 weeks; otherwise, the patient was withdrawn from the study. Treatment was not continued after treatment cycle day 14 regardless of the number of days the drug was interrupted. Treatment was administered until disease progression, intolerable toxicity, or consent withdrawal.

\section{Evaluation of efficacy and toxicities}

Evaluations before chemotherapy included obtaining patient's medical history, physical examination, complete blood count, 
blood chemistry, chest X-ray, and abdominal computed tomography $(\mathrm{CT})$. After starting the protocol treatment, complete blood count was examined weekly and blood chemistry every 3 weeks. Detailed medical history, physical examinations, and treatment-related toxicities were recorded weekly. Tumour size was measured by imaging studies every 6 weeks. Tumour response was evaluated according to the Response Evaluation Criteria in Solid Tumors (RECIST) criteria (Therasse et al, 2000). All patients with tumour responses (complete or partial response) received a confirmatory scan 4 weeks following the initial documentation.

Toxicities were graded, from the time of study entry through 30 days after the last dose of study medication was administered, according to the National Cancer Institute-Common Terminology Criteria for Adverse Events (v3.0) (Trotti et al, 2003).

\section{Statistical methods}

The treatment programme was designed to reject a response rate of $<25 \%(\mathrm{P} 0)$ and to provide a statistical power of 0.80 in assessing the activity of the regimen as $50 \%(\mathrm{P} 1)$ with an $\alpha$-error of 0.05 . A total of 37 patients were therefore required. Time to progression was defined as the duration from the date of starting protocol treatment to the date of disease progression. Data of patients who were lost to follow-up before progression were censored at the date of their last CT scan. Overall survival represented the duration from the date of starting protocol treatment to the date of death from any cause. Survival was estimated by the Kaplan-Meier analysis. All statistics were two-sided and performed using SAS software (version 9.1.3, SAS Inc., Cary, NC, USA).

\section{RESULTS}

\section{Patients and treatment}

Between August 2007 and March 2009, 45 patients from five medical centres were enrolled in the study. Their clinicopathological

Table I Clinicopathologic features of the patients

\begin{tabular}{|c|c|}
\hline & Patient number (\%) \\
\hline Total patients & 45 \\
\hline Age (years), median (range) & $56(22-75)$ \\
\hline Sex: male/female & $27 / 18$ \\
\hline \multicolumn{2}{|l|}{ ECOG performance } \\
\hline 0 & $20(44)$ \\
\hline 1 & $23(5 \mid)$ \\
\hline 2 & $2(4)$ \\
\hline \multicolumn{2}{|l|}{ Treatments for primary tumour } \\
\hline No previous therapy & $9(20)$ \\
\hline Surgery only & $27(60)$ \\
\hline Surgery+adjuvant chemotherapy & $7(16)$ \\
\hline Radiotherapy & $2(4)$ \\
\hline \multicolumn{2}{|l|}{ Disease status } \\
\hline Locally advanced & $4(9)$ \\
\hline Recurrence/metastasis & $4 \mid(9 \mid)$ \\
\hline \multicolumn{2}{|l|}{ Disease sites } \\
\hline Liver & $9(20)$ \\
\hline Lymph nodes & $34(76)$ \\
\hline Peritoneum & I (2) \\
\hline Gastrointestinal tract & $25(56)$ \\
\hline Bone & $2(4)$ \\
\hline Lung & $0(0)$ \\
\hline Others & $24(53)$ \\
\hline
\end{tabular}

characteristics are listed in Table 1. A total of 271 (median: 6; range: $1-21)$ cycles of chemotherapy were given. The median relative dose intensity was $82 \%$ (range: $46-100 \%$ ) for docetaxel, $80 \%$ (range: $46-100 \%$ ) for cisplatin, 95\% (range: $54-100 \%$ ) for tegafur/uracil, and $95 \%$ (range: $54-100 \%$ ) for leucovorin. In total, $62 \%$ of the patients received more than $80 \%$ of the intended doses of docetaxel, $53 \%$ received more than $80 \%$ of the intended doses of cisplatin, and $89 \%$ received more than $80 \%$ of the intended doses of tegafur/uracil and leucovorin.

\section{Efficacy}

Five patients were not evaluable for responses: three failed to return for tumour measurements, one was later found to have protocol violation, and one refused further chemotherapy after one treatment cycle. Among the 40 evaluable patients, the best tumour response was complete response in 1, partial response (PR) in 22, stable disease in 11, and progressive disease in 6 . The overall response rates of the evaluable and intent-to-treat (ITT) populations were 58\% (95\% CI: $41-74 \%$ ) and 53\% (95\% CI: $38-68 \%$ ), respectively, whereas the disease control rate in according population was $85 \%$ (95\% CI: $70-94 \%)$ and $82 \%$ (95\% CI: $68-92 \%)$, respectively. The response rates of patients with $\geqslant 80$ and $<80 \%$ of the scheduled docetaxel dose intensity were $58 \%$ (19 out of 33$)$ and $57 \%$ ( 4 out of 7$)$, respectively $(P=1.0000)$. The response rates of patients with $\geqslant 80$ and $<80 \%$ of scheduled cisplatin dose intensity were $62 \%$ (18 out of 29 ) and $45 \%$ (5 out of $11)$, respectively $(P=0.7665)$. The response rates of patients with $\geqslant 80$ and $<80 \%$ of scheduled tegafur/uracil dose intensity were $57 \%$ (20 out of 35 ) and $60 \%$ ( 3 out of 5$)$, respectively $(P=1.0000)$. Median time to tumour response was 1.8 (range: $1.2-6.4$ ) months. Median duration of tumour response was 5.5 (range: 2.4-14.9) months. Of the 45 patients, 28 received second-line therapies. Among them, 19 patients received cisplatin plus 5-FU and leucovorin, 4 patients received oxaliplatin plus 5-FU and leucovorin, 1 patient received oxaliplatin plus tegafur/uracil and leucovorin, 1 patient received 5-FU and leucovorin, 1 patient received oxaliplatin and capecitabine, 1 patient received cisplatin plus 5-FU, leucovorin, and cetuximab, and 1 patient received everolimus.

Median follow-up time was 13.3 (range: 1.7-27.8) months. Median TTP and OS were 6.8 (95\% CI: $2.3-11.3$ ) months and 13.9 (95\% CI: 10.7-17.2) months, respectively. The Kaplan-Meier estimated TTP and OS curves are shown in Figures 1 and 2, respectively. The fraction of patients alive at 1 year was $60 \%$ and at 2 years was $7 \%$.

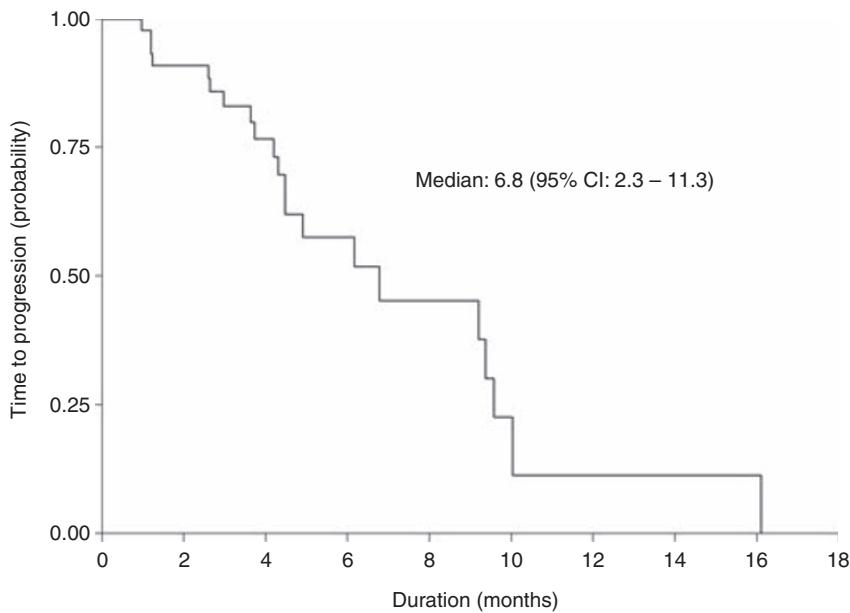

Figure I Time to progression of the 45 patients. 


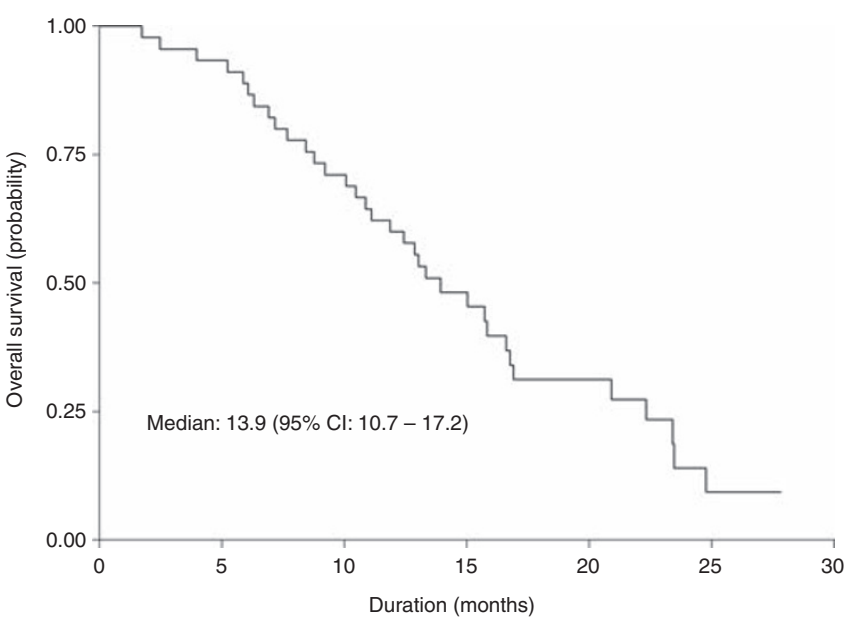

Figure 2 Overall survival of the 45 patients.

Table 2 Percentages of toxicity of the docetaxel, cisplatin, tegafur/uracil, and leucovorin regimen

\begin{tabular}{|c|c|c|c|c|c|c|c|c|}
\hline \multirow[b]{3}{*}{ Toxicity } & \multicolumn{4}{|c|}{ Patients $(n=45)$} & \multicolumn{4}{|c|}{ Cycles $(n=27 I)$} \\
\hline & \multicolumn{2}{|c|}{ Grade } & \multicolumn{2}{|c|}{ Grade } & \multicolumn{2}{|c|}{ Grade } & \multicolumn{2}{|c|}{ Grade } \\
\hline & $\mathbf{I}$ & 2 & 3 & 4 & $\mathbf{I}$ & 2 & 3 & 4 \\
\hline \multicolumn{9}{|l|}{ Haematological } \\
\hline Neutropenia & $4^{\mathrm{a}}$ & 11 & 33 & 18 & $11^{\mathrm{b}}$ & 13 & 17 & 6 \\
\hline Leukopenia & 7 & 31 & 24 & 9 & 17 & 16 & 10 & 1 \\
\hline Thrombocytopenia & 18 & 9 & 2 & 2 & 21 & 2 & 0.4 & 0.4 \\
\hline Febrile neutropenia $^{c}$ & 0 & 0 & 4 & 0 & 0 & 0 & I & 0 \\
\hline Anaemia & 2 & 58 & 22 & 0 & 4 & 27 & 5 & 0 \\
\hline \multicolumn{9}{|l|}{ Gastrointestinal } \\
\hline Nausea & 31 & 22 & 7 & 0 & 19 & 6 & 1 & 0 \\
\hline Vomiting & 22 & 29 & 4 & 0 & 12 & 7 & I & 0 \\
\hline Diarrhoea & 22 & 33 & 13 & 2 & 16 & 14 & 3 & 0 \\
\hline Stomatitis & 13 & 22 & 7 & 0 & 5 & 11 & 4 & 0 \\
\hline Anorexia & 24 & 24 & 4 & 0 & 18 & 6 & 8 & 0 \\
\hline Weight loss & 20 & 16 & 2 & 0 & 10 & 6 & 0.4 & 0 \\
\hline Neurosensory & 7 & 2 & 0 & 0 & 10 & 1 & 0 & 0 \\
\hline \multicolumn{9}{|l|}{ Others } \\
\hline Hand and foot syndrome & 4 & 4 & 0 & 0 & 3 & 5 & 0 & 0 \\
\hline Fever & 16 & 7 & 0 & 0 & 6 & I & 0 & 0 \\
\hline Infections & 11 & 16 & 20 & 0 & 5 & 5 & 7 & 0 \\
\hline Alopecia & 36 & 9 & 0 & 0 & 31 & 5 & 0 & 0 \\
\hline
\end{tabular}

${ }^{a}$ All numbers are percentages of the 45 patients. ${ }^{b}$ All numbers are percentages of the 271 cycles given. ${ }^{\circ}$ Febrile neutropenia was defined as fever of unknown origin without clinically or microbiologically documented infection with absolute neutrophil count $<1.0 \times 10^{9} / 1$ and fever $\geqslant 38.5^{\circ} \mathrm{C}$, according to the National Cancer Institute Common Terminology Criteria for Adverse Events 3.0.

\section{Toxicity}

All patients were evaluated for toxicities (Table 2). The most common toxicity was neutropenia, with grades 3-4 neutropenia observed in $51 \%$ of the patients. Two patients developed neutropenic fever and recovered with appropriate therapy. Grade 3 anaemia was observed in $22 \%$ of the patients. Grades 3-4 diarrhoea developed in seven patients $(16 \%)$. Grade 3 infections occurred in nine patients $(20 \%)$, with one device-related infection, one nail infection, one wound infection, one urinary tract infection, and five pneumonia. A total of $36(80 \%)$ patients had dose delays during treatment. Dose modification to level-1 was required in 19 (42\%) patients, whereas level-2 dose modification was required in two patients (4\%). Treatment-related toxicity resulted in treatment discontinuation in eight (18\%) patients, which were associated with neutropenia in two, thrombocytopenia in two, pneumonia in two, anaemia in one and serum creatinine increased in one. There was no treatment-related mortality.

\section{DISCUSSION}

The V325 study showed that docetaxel in combination with cisplatin and 5-FU (DCF) could become a new standard therapy for the treatment of advanced gastric cancer (Van Cutsem et al, 2006). However, grade 3 or 4 neutropenia occurred in $82 \%$ of patients on DCF. The high incidence of neutropenia becomes a critical issue for clinical application of the DCF regimen. Recently, the superior therapeutic index of weekly docetaxel over the 3-weekly schedule has been demonstrated in gastric cancer patients (Ajani et al, 2005; Evans et al, 2007b; Roth et al, 2007; Wang et al, 2009). With comparable tumour response rates $(37-48 \%)$ for advanced gastric cancer, grades 3-4 neutropenia of weekly docetaxel $\left(33.3 \mathrm{mg} \mathrm{m}^{-2}\right.$, on days 1,8 , and 15 every 4 weeks or $40 \mathrm{mg} \mathrm{m}^{-2}$, on day 1 and 8 every 3 weeks) was less common than that of 3-weekly docetaxel $\left(75-85 \mathrm{mg} \mathrm{m}^{-2}\right.$, on day 1 every 3 weeks) ( $<10-48$ vs $\left.57-86 \%\right)$. Weekly docetaxel and platinum plus either infusional 5-FU or oral fluoropyrimidine have become popular investigational combinations for advanced gastric cancers (Chen et al, 2002; Evans et al, 2007a, b; Wang et al, 2009).

This is the first phase II study investigating weekly docetaxel and platinum plus oral fluoropyrimidine in treating advanced gastric cancer. The $58 \%$ overall response rate of the evaluable patients (53\% on ITT analyses), median survival of 13.9 months and grades 3-4 neutropenia in $51 \%$ of participants are not inferior to the results of other phase II clinical trials with topoisomerase I inhibitor-, taxane-, or third-generation oral fluoropyrimidinebased (i.e., S-1 and capecitabine) doublet chemotherapy regimens (Schoffski, 2002; Ohtsu, 2005), in which the objective tumour response rate and median survival ranged from 40 to $76 \%$ and from 9 to 12.5 months, respectively. The median survival in this study was also comparable with those achieved in previous highdose 5-FU and leucovorin-based studies in Taiwan (Hsu et al, 1997; Chen et al, 2002; Chao et al, 2004, 2006), and to the 6.1-12.0 months median survival of phase II or III studies of current 'reference' regimens for advanced gastric cancers, that is, ECF, FAMTX, ELF, FUP, FOLFOX-6, and DCF (Webb et al, 1997; Vanhoefer et al, 2000; De Vivo et al, 2000; Louvet et al, 2002; Ohtsu, 2005; Van Cutsem et al, 2006).

The overall response rates of evaluable and ITT populations were 58 and $53 \%$ in this study. Among other docetaxel-based studies, the tumour response rate ranged from 37 to $43 \%$ in chemo-naive gastric cancer patients (Ajani et al, 2005; Van Cutsem et al, 2006; Roth et al, 2007). The OS of 13.9 months, TTP of 6.8 months, and toxicity profiles (51\% grades 3-4 neutropenia) of the current regimen are also comparable with those observed in previous docetaxel-based trials (OS 9.2-10.4 months, TTP 4.6-5.9 months, and 57-86\% grades 3-4 neutropenia) (Ajani et al, 2005; Van Cutsem et al, 2006; Roth et al, 2007). Although this regimen was less toxic than other previously described combination therapies, the incidence of grade 4 neutropenia (18\%) and treatment discontinuation due to treatment-related toxicity (18\%) was still high. Further modification of the dosage of this regimen or addition of prophylactic G-CSF should be considered in the management of these patients. On the other hand, $76 \%$ of our patients had undergone gastrectomy previously, and the incidence of liver metastasis $(20 \%)$ or peritoneal seeding $(2 \%)$ was relatively low compared with that in other studies. A large proportion of recurrent disease and low tumour burden could have contributed to the good response rate and survival results in this study (Lee et al, 2007). 
The advantages of oral fluoropyrimidine include the alleviation of the requirement and cost of central venous catheter implantation and the inconvenience of an infusion pump, which in turn may improve the quality of life of treated patients. In this study, we used tegafur/uracil replacing infusional 5-FU. Both tegafur/uracil and capecitabine are commonly used oral fluoropyrimidines and have similar antitumor activities (Twelves et al, 2005; Lembersky et al, 2006). Capecitabine has a higher rate of grades 3 and 4 hand foot syndrome, whereas tegafur/uracil has a higher rate of grades 3 and 4 diarrhoea (Twelves et al, 2005; Lembersky et al, 2006). This is consistent with our findings of no grades 3 and 4 hand foot syndrome, but occurrence of grade 3 diarrhoea in $13 \%$ of our patients.

Orditura et al (2006) reported that weekly docetaxel and capecitabine is not effective in the treatment of advanced gastric cancer. In that study, the dose of docetaxel was similar to that of our current study, whereas the dose of capecitabine was relatively low at $625 \mathrm{mg} \mathrm{m}^{-2}$ twice daily per os on days 5-18 repeated every 4 weeks, which may be inadequate for gastric cancer. Despite a low rate of myelosuppression, diarrhoea, and hand foot syndrome, the response rate was only $21 \%$. In our study, the higher response rate could be due to adequate tegafur/uracil dosage $\left(300 \mathrm{mg} \mathrm{m}^{-2}\right.$ per day as recommended for gastric cancer). Moreover, there was a synergistic effect among cisplatin, tegafur/uracil, and docetaxel (Maeda et al, 2004; Kodera et al, 2005).

Recently, several novel targeted therapeutic agents such as inhibitors of epidermal growth factor receptor or of vascular

\section{REFERENCES}

Ajani JA, Fodor MB, Tjulandin SA, Moiseyenko VM, Chao Y, Cabral Filho S, Majlis A, Assadourian S, Van Cutsem E (2005) Phase II multi-institutional randomized trial of docetaxel plus cisplatin with or without fluorouracil in patients with untreated, advanced gastric, or gastroesophageal adenocarcinoma. J Clin Oncol 23: 5660-5667

Chao Y, Li CP, Chao TY, Su WC, Hsieh RK, Wu MF, Yeh KH, Kao WY, Chen LT, Cheng AL (2006) An open, multi-centre, phase II clinical trial to evaluate the efficacy and safety of paclitaxel, UFT, and leucovorin in patients with advanced gastric cancer. Br J Cancer 95: $159-163$

Chao Y, Yeh KH, Chang CJ, Chen LT, Chao TY, Wu MF, Chang CS, Chang JY, Chung CY, Kao WY, Hsieh RK, Cheng AL (2004) Phase II study of weekly oxaliplatin and 24-h infusion of high-dose 5-fluorouracil and folinic acid in the treatment of advanced gastric cancer. $B r$ J Cancer 91: $453-458$

Chen LT, Liu TW, Wu CW, Chung TR, Shiah HS, Jan CM, Liu JM, WhangPeng J, Chang JY (2002) A phase I study of weekly docetaxel, 24-h infusion of high-dose fluorouracil/leucovorin and cisplatin in patients with advanced gastric cancer. Oncology 63: 239-247

Chong G, Cunningham D (2005) Gastrointestinal cancer: recent developments in medical oncology. Eur J Surg Oncol 31: 453-460

De Vivo R, Pignata S, Palaia R, Parisi V, Daniele B (2000) The role of chemotherapy in the management of gastric cancer. J Clin Gastroenterol 30: $364-371$

Dupont Jr JB, Lee JR, Burton GR, Cohn Jr I (1978) Adenocarcinoma of the stomach: review of 1,497 cases. Cancer 41: $941-947$

Evans D, Miner T, Akerman P, Millis R, Jean M, Kennedy T, Safran H (2007a) A phase I study of docetaxel, oxaliplatin, and capecitabine in patients with metastatic gastroesophageal cancer. Am J Clin Oncol 30: $346-349$

Evans D, Miner T, Iannitti D, Akerman P, Cruff D, Maia-Acuna C, Harrington D, Habr F, Chauhan B, Berkenblit A, Stuart K, Sears D, Kennedy T, Safran H (2007b) Docetaxel, capecitabine and carboplatin in metastatic esophagogastric cancer: a phase II study. Cancer Invest 25: $445-448$

Hainsworth JD, Burris III HA, Erland JB, Thomas M, Greco FA (1998) Phase I trial of docetaxel administered by weekly infusion in patients with advanced refractory cancer. J Clin Oncol 16: 2164-2168

Hsu CH, Yeh KH, Chen LT, Liu JM, Jan CM, Lin JT, Chen YC, Cheng AL (1997) Weekly 24-h infusion of high-dose 5-fluorouracil and leucovorin endothelial growth factor, when in combination with chemotherapy, have shown promising activity against gastrointestinal cancers (Chong and Cunningham, 2005). The low-toxicity profiles of such agents also provide an excellent chance to improve the therapeutic index of this active and convenient regimen for advanced gastric cancer patients.

In conclusion, the combination of weekly docetaxel, cisplatin and oral tegafur/uracil, and leucovorin is an active, outpatientbased chemotherapy regimen with acceptable toxicities. Strategies to improve the therapeutic index of the current regimen, such as administration in combination with novel biological-targeted agents, should be further explored.

\section{ACKNOWLEDGEMENTS}

This work was supported by TTY Biopharm, Taipei, Taiwan, Grant number NSC 98-2314-B-075-029 from the National Science Council, Grant number VGH 99C1-107 from Taipei Veterans General Hospital, and Grant number DOH 99-TD-C-111-007 from the Department of Health, Taiwan, and assisted, in part, by the Division of Experimental Surgery of the Department of Surgery, Taipei Veterans General Hospital.

\section{Conflict of interest}

The authors declare no conflict of interest. in the treatment of advanced gastric cancers. An effective and low-toxic regimen for patients with poor general condition. Oncology 54: 275-280 Kodera Y, Fujiwara M, Yokoyama H, Ohashi N, Miura S, Ito Y, Koike M, Ito K, Nakao A (2005) Combination of oral fluoropyrimidine and docetaxel: reappraisal of synergistic effect against gastric carcinoma xenografts. In Vivo 19: $861-866$

Kunitoh H, Watanabe K, Onoshi T, Furuse K, Niitani H, Taguchi T (1996) Phase II trial of docetaxel in previously untreated advanced nonsmall-cell lung cancer: a Japanese cooperative study. J Clin Oncol 14: $1649-1655$

Lee SS, Lee JL, Ryu MH, Chang HM, Kim TW, Kang HJ, Kim WK, Lee JS, Kang YK (2007) Combination chemotherapy with capecitabine (X) and Cisplatin (P) as first line treatment in advanced gastric cancer: experience of 223 patients with prognostic factor analysis. Jpn J Clin Oncol 37: $30-37$

Lembersky BC, Wieand HS, Petrelli NJ, O'Connell MJ, Colangelo LH, Smith RE, Seay TE, Giguere JK, Marshall ME, Jacobs AD, Colman LK, Soran A, Yothers G, Wolmark N (2006) Oral uracil and tegafur plus leucovorin compared with intravenous fluorouracil and leucovorin in stage II and III carcinoma of the colon: results from National Surgical Adjuvant Breast and Bowel Project Protocol C-06. J Clin Oncol 24: $2059-2064$

Louvet C, Andre T, Tigaud JM, Gamelin E, Douillard JY, Brunet R, Francois E, Jacob JH, Levoir D, Taamma A, Rougier P, Cvitkovic E, de Gramont A (2002) Phase II study of oxaliplatin, fluorouracil, and folinic acid in locally advanced or metastatic gastric cancer patients. J Clin Oncol 20: $4543-4548$

Maeda S, Sugiura T, Saikawa Y, Kubota T, Otani Y, Kumai K, Kitajima M (2004) Docetaxel enhances the cytotoxicity of cisplatin to gastric cancer cells by modification of intracellular platinum metabolism. Cancer Sci 95: $679-684$

McNeer G, Vandenberg Jr H, Donn FY, Bowden L (1951) A critical evaluation of subtotal gastrectomy for the cure of cancer of the stomach. Ann Surg 134: $2-7$

Ohtsu A (2005) Current status and future prospects of chemotherapy for metastatic gastric cancer: a review. Gastric Cancer 8: 95-102

Orditura M, Martinelli E, Galizia G, Carlomagno C, Aurilio G, Vecchione L, Lieto E, De Placido S, Catalano G, Ciardiello F, De Vita F (2006) Weekly docetaxel and capecitabine is not effective in the treatment of advanced gastric cancer: a phase II study. Ann Oncol 17: 1529-1532 
Roder DM (2002) The epidemiology of gastric cancer. Gastric Cancer 5(Suppl 1): 5-11

Roth AD, Fazio N, Stupp R, Falk S, Bernhard J, Saletti P, Koberle D, Borner MM, Rufibach K, Maibach R, Wernli M, Leslie M, Glynne-Jones R, Widmer L, Seymour M, de Braud F (2007) Docetaxel, cisplatin, and fluorouracil; docetaxel and cisplatin; and epirubicin, cisplatin, and fluorouracil as systemic treatment for advanced gastric carcinoma: a randomized phase II trial of the Swiss Group for Clinical Cancer Research. J Clin Oncol 25: $3217-3223$

Schoffski P (2002) New drugs for treatment of gastric cancer. Ann Oncol 13(Suppl 4): 13-22

Schuette W, Nagel S, Blankenburg T, Lautenschlaeger C, Hans K, Schmidt EW, Dittrich I, Schweisfurth H, von Weikersthal LF, Raghavachar A, Reissig A, Serke M (2005) Phase III study of second-line chemotherapy for advanced non-small-cell lung cancer with weekly compared with 3-weekly docetaxel. J Clin Oncol 23: 8389-8395

Therasse P, Arbuck SG, Eisenhauer EA, Wanders J, Kaplan RS, Rubinstein L, Verweij J, Van Glabbeke M, van Oosterom AT, Christian MC, Gwyther SG (2000) New guidelines to evaluate the response to treatment in solid tumors. European Organization for Research and Treatment of Cancer, National Cancer Institute of the United States, National Cancer Institute of Canada. J Natl Cancer Inst 92: 205-216

Trotti A, Colevas AD, Setser A, Rusch V, Jaques D, Budach V, Langer C, Murphy B, Cumberlin R, Coleman CN, Rubin P (2003) CTCAE v3.0: development of a comprehensive grading system for the adverse effects of cancer treatment. Semin Radiat Oncol 13: 176-181

Twelves C, Wong A, Nowacki MP, Abt M, Burris III H, Carrato A, Cassidy J, Cervantes A, Fagerberg J, Georgoulias V, Husseini F, Jodrell D, Koralewski P, Kroning H, Maroun J, Marschner N, McKendrick J, Pawlicki M, Rosso R, Schuller J, Seitz JF, Stabuc B, Tujakowski J,
Van Hazel G, Zaluski J, Scheithauer W (2005) Capecitabine as adjuvant treatment for stage III colon cancer. $N$ Engl J Med 352: 2696-2704

Van Cutsem E, Moiseyenko VM, Tjulandin S, Majlis A, Constenla M, Boni C, Rodrigues A, Fodor M, Chao Y, Voznyi E, Risse ML, Ajani JA (2006) Phase III study of docetaxel and cisplatin plus fluorouracil compared with cisplatin and fluorouracil as first-line therapy for advanced gastric cancer: a report of the V325 Study Group. J Clin Oncol 24: 4991 - 4997

Vanhoefer U, Rougier P, Wilke H, Ducreux MP, Lacave AJ, Van Cutsem E, Planker M, Santos JG, Piedbois P, Paillot B, Bodenstein H, Schmoll HJ, Bleiberg H, Nordlinger B, Couvreur ML, Baron B, Wils JA (2000) Final results of a randomized phase III trial of sequential high-dose methotrexate, fluorouracil, and doxorubicin $v s$ etoposide, leucovorin, and fluorouracil $v s$ infusional fluorouracil and cisplatin in advanced gastric cancer: A trial of the European Organization for Research and Treatment of Cancer Gastrointestinal Tract Cancer Cooperative Group. J Clin Oncol 18: 2648-2657

Verdecchia A, Mariotto A, Gatta G, Bustamante-Teixeira MT, Ajiki W (2003) Comparison of stomach cancer incidence and survival in four continents. Eur J Cancer 39: $1603-1609$

Wang B, Zhang W, Hong X, Guo Y, Li J (2009) Phase I dose-escalating study of 24-h continuous infusion of 5-fluorouracil in combination with weekly docetaxel and cisplatin in patients with advanced gastric cancer. Cancer Chemother Pharmacol 63: 213-218

Webb A, Cunningham D, Scarffe JH, Harper P, Norman A, Joffe JK, Hughes M, Mansi J, Findlay M, Hill A, Oates J, Nicolson M, Hickish T, O’Brien M, Iveson T, Watson M, Underhill C, Wardley A, Meehan M (1997) Randomized trial comparing epirubicin, cisplatin, and fluorouracil vs fluorouracil, doxorubicin, and methotrexate in advanced esophagogastric cancer. J Clin Oncol 15: $261-267$ 